\title{
Biosafety and Biosecurity Still Big Challenges for Health Care Sector and to Researchers
}

\section{Leila Macedo*}

President of ANBio (National Biosafety Association, Brazil)

Since years 1950, Pike and Sulkin have started mapping nosocomial infections in the laboratories working with biological material. The biggest challenge at that time was to count with accurate data on those infections. The data available was ever underestimated and for many reasons researchers and lab workers did not like to say that he or she has been submitted to an incident or accident with a potential infective material.

Considering Hospital Acquired Infections- HAI since the time of Semmelweis in 1846 he has observed that simple habits, like washing hands appropriately should reduce the infections in the hospital and could save lives. Nowadays, after almost two centuries, even with new technologies available and the enhancement of capacity building programs on Biosafety and Biosecurity we deal with the same problems, with additional ones. It is known that HAI is growing each day. Even been underestimated, we know that levels of MRSA, KPC and TB multiresistant to drugs are increasing the number of deaths in hospitals.

Dual Use Research of Concern (DURC) - studies whose results could be used for good or harm- gained currency in the wake of the controversy that erupted late in 2011 over experiments in which two teams of scientists developed lab-modified H5N1 viruses capable of airborne transmission in ferrets. Also the recent H7N9 outbreaks and infections of lab workers with the New $\mathrm{CoV}$ raised the issue of the fragility of communities to new Bio Risks. The question we have to answer is: what is missing? Why are we always running against time when talking about fighting against challenges in public health? It seems that virus and all the super bugs, either natural or created by man are much more "intelligent' than the humans. The lack of global guidance or a framework for management of DURC that bridges the many stakeholder communities is one of the critical gaps. However, even simple measures like enhancing awareness on the importance of notifying accidents, as well as hospital acquired infections and a continuous survey system for biological material of concern available in the labs are critical to .improve Biosafety and Biosecurity worldwide. Are scientists, lab workers, hospital personnel and managers conscious of their responsibilities and duties?

Recently, Dr. Stephen Lewis, Director of the "AIDS-Free World" that supported the United Nations Development Program UNAIDS, said in his opening speech during the II Conference of the International Federation of Biosafety Associations- IFBA in South Africa, that "the world will never become free from AIDS-HIV or any other biological enemy if there is not a big commitment by all Governments, donors and all stakeholders to guarantee Biosafety and Biosecurity measures in health care sector and laboratories". The full engagement of the Biosafety community in this discussion and the commitment of Governments with the Biosafety cause will represent the big missing differential not taken yet to give the step forward.

The vulnerability of public spaces, like hospitals, as the 'new' terrorist threat, has been showed by recent researches on health care buildings and how gaps in the system create the potential for failure across layers of the organization. Perhaps one of the greatest challenges to health care managers and to governments, particularly in an evidence-based world, is how to plan for events that have no a priori evidence -- especially when resource allocation is often contingent on a rational business case. The open and permeable nature of health care will remain its main vulnerability, and acknowledge the difficulty of raising awareness of risks among staff, patients and the local population. Pointing out also that there are potential risks from available biological material in the labs that are not frequently checked and that can be misused.

The cost of health care services is being higher and higher as patients enter in the hospitals and acquire new infections. The cost of dealing with HAI is much higher than to improve hospital facilities and establish Biosafety and Biosecurity procedures to be followed. Also, considering laboratory acquired infections (LAI) it shows that there is a big vulnerability of workers and also the risk of misuse of potential biological materials that can cause arm to the population and impacts in the economy.

Biosafety and Biosecurity plans should be taken as rigorous long term projects which will lead a better health system. The implementation of proactive Biosafety and Biosecurity Policies and programs by Governments and organizations committed to public health leads to better infections disease research, surveillance and diagnosis and more effective global disease prevention and treatment while avoiding the misuse of biological material. The complexity of the problem requires a commitment of all stakeholders with the Bio Risk management cause which on the other hand will improve quality of life and reduce the socio-economic impact due to the disruption of safety and security due to unexpected new threat.
*Corresponding author: Leila Macedo, President, ANBio, Brazil, E-mail: leila.macedo10@uol.com.br

Received May 30, 2013; Accepted June 01, 2013; Published June 03, 2013

Citation: Macedo L (2013) Biosafety and Biosecurity Still Big Challenges for Health Care Sector and to Researchers. J Biosafety Health Educ 1: e109. doi:10.4172/ 2332-0893.1000e109

Copyright: (c) 2013 Macedo L. This is an open-access article distributed under the terms of the Creative Commons Attribution License, which permits unrestricted use, distribution, and reproduction in any medium, provided the original author and source are credited. 